\section{Dumpling soup}

\author{
John Launer
}

Last year I ran a modular course for a group of GP trainers in Israel. I went out there three times, for a few days at a time, to teach a model of communication skills. Most of the work was interactional, done in small groups or discussion by the whole class. However, there was a need for theoretical learning, so I prepared some presentations on the underlying theory of the model, drawn from a variety of sources including communication theory, complex adaptive systems, and narrative studies.

The relationship between theory and practice is an interesting one, especially in an area like communication skills. Some people seem able to master the theory easily but cannot actually apply it. Others seem naturally gifted in communicating with patients but beyond a certain point they get frustrated by doing this without exactly knowing why. They want to know more about the principles that govern good communication. So the question arises-for both kinds of people-what is the ideal balance between learning the theory and just practising? This question came up a lot in discussion during the Israeli course and together we came up with an answer: dumpling soup.

Now, in order to understand this improbable answer, you first need a bit of cultural background. Dumpling soup (most commonly chicken soup with dumplings in it) is a proverbial dish in Israeli and European Jewish culture. It is a staple of every home. Everyone claims that their own mother's soup-or grandmother's-is superior to any other soup they have ever tasted. Mothers and grandmothers traditionally make it for a child who is ill, so it has acquired the well-known description of 'Jewish penicillin'. But it is also important to get the consistency of the dumplings exactly right, hence the equally well-known curse: 'May your bullets turn into dumplings and your dumplings into bullets'. And it is important to put the right number of dumplings into each bowl of soup. Too few dumplings and it isn't really dumpling

Correspondence to Dr John Launer, London Deanery, Stewart House, London WC1B 5DN, UK;

jlauner@londondeanery.ac.uk soup. Too many, and it isn't a soup any more.

Taking this cultural knowledge into account, you can probably now see its applicability to the dilemma of how much theory to include on a practical course in communication skills. However, once we had hit on the metaphor out of pure fun, we found it carried more philosophical weight than we expected. Dumpling soup moved from being a pleasant joke to becoming a powerful symbol for what we were trying achieve: a mode of medical communication that was both spontaneous and disciplined at the same time.

\section{UNCERTAINTY}

When you meet with patients, or talk with colleagues, you need to hold on to a great deal of uncertainty about where the conversation might take you: one might call this a fluid part of the soup, or the 'soupiness'. You need to make an act of faith in diving into the conversational soup without any expectations or presuppositions. A number of experts on therapeutic communication have described this position with terms such as 'curiosity' or 'not knowing'. The psychoanalyst Wilfred Bion proposed that an ideal therapeutic conversation should start without 'memory, desire or understanding': instead it should be directed by ideas emerging from the unconscious, and without trying to exert control. ${ }^{3}$ If you cannot start with an act of faith like this, any conversation can become oppressive, with the more powerful person (eg, the doctor in a consultation or the trainer in a tutorial) generally taking over.

At the same time, an over-soupy conversation may ramble all over the place, or degenerate into gossip. It may also carry on indefinitely. The person being paid to conduct the conversation-the physician, or the teacher-needs to have a firm grasp on the context of the conversation, its purpose and appropriate communication technique. It is these that form much of the material of theory. You can see them as the dumplings.

When learning communication skills, doctors really do need to address some basic theoretical issues. These include questions like 'who am I accountable to?', 'what are they each expecting from me?' and 'how do I best hold a conversation that achieves all those ends?' These are not simple questions. The answers often involve a balance of conflicting principles. A serious theoretical discussion of them may need to encompass ethics, the law, regulations, psychology, culture, language and a great deal more-not to mention the basic stuff of medicine including diagnosis and evidence. These subjects are all dumplings and quite substantial ones at that.

\section{TAKING RISKS}

On the course itself, we noticed that there were soupy moments when everyone felt rather lost. They were having conversations with each other about cases or training encounters, and the dialogue seemed free and easy enough, but was also going nowhere. We learnt to notice these soupy moments, and to take the opportunity to pause and pull together the ingredients for a few dumplings. We needed to ask why the participants had lost their hold on context, purpose or technique, and to find the theoretical principles to describe this. Typically, at such moments, I gave a short theory presentation. We also learnt that, after you have thrown in a few theoretical dumplings in this way, you can get overfull. The discussion becomes too stodgy, and you have to leave the theory behind once more, let yourself go, and take risks. In other words, you have to become soupy again.

One of the ideas that followed from this discovery is that, in professional practice, it may be useful to carry around a kind of emotional soup-and-dumpling detector. In any medical conversation there may be times, for example, where you feel you have quite lost the plot and are swimming around aimlessly. These are the moments when you have to search for dumplings and ask yourself some fundamental questions about your role, your intentions, and the way you are conducting the conversation. At other times, you may find that the conversation becomes tense or adversarial. It may be that you have become too governed by theoretical notions of what you must say or do in a situation like this. These are classical moments of dumpling excess. You may need to toss a few of your cherished dumplings out of the bowl and allow the conversation to flow freely and soupily again.

There are many technical terms in the world of communication skills. They span the centuries from Aristotle's idea of 
'phronesis' (practical wisdom) to Donald Schön's famous distinction between 'reflection-in-action' and 'reflection-onaction'. I would like to think that that the concept of dumpling soup may find a similar place in world intellectual history. I am very grateful to my Israeli colleagues for cooking up the idea.

Contributors John Launer.
Competing interests None.

Provenance and peer review Commissioned; internally peer reviewed.

Postgrad Med J 2012;88:243-244.

doi:10.1136/postgradmedj-2012-130911

\section{REFERENCES}

1. Cecchin G. Hypothesising, circularity and neutrality revisited: an invitation to curiosity. Fam Proc 1987;26:405-13
2. Anderson H, Goolishian $\mathrm{H}$. The client is the expert: a not-knowing approach to therapy. In: McNamee S, Gergen K, eds. Therapy as Social Construction. London: Sage, 1992.

3. Bion W. Notes on memory and desire. Psychoanalytic Forum 1967:2:271-80.

4. Schön D. The Reflective Practitioner: How Professionals Think in Action. London: Temple Smith, 1983. 